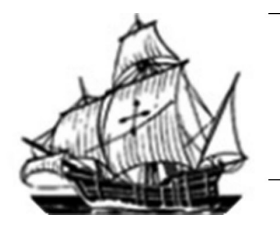

\title{
Sérgio Vaz e João Melo: abordagem de espaços urbanos
}

\author{
Bruna Borges de Almeida ${ }^{1}$
}

\begin{abstract}
Resumo: Entendendo que a autoria se constitui no texto literário enquanto função, exercendo um papel em relação ao discurso, pretende-se analisar a forma como os autores Sérgio Vaz e João Melo representam os sujeitos e espaços sociais pouco privilegiados e como problematizam a autoria nos livros Literatura, pão e poesia (2011) e Filhos da Pátria (2008). Servem como embasamento teórico as análises de Pierre Bourdieu (1996) sobre a gênese discursiva e as relações de poder que a perpassam; e de Michel Foucault (2006) na abordagem do poder do discurso, seus efeitos sociais e a função autoral. As análises de Foucault (1970) também contribuem para este estudo, levando em conta o discurso não só como um meio de disputas ou tradução de sistemas de dominação, mas como o próprio objeto pelo qual se travam disputas. Essa disputa por legitimidade discursiva no meio literário é encontrada com mais contundência nos escritos de Sérgio Vaz, que trata a literatura como o pão da sabedoria comungado pelos sujeitos periféricos que construíram um espaço próprio para o consumo dos bens literários, já que estão excluídos dos meios de circulação da cultura. Embora não da mesma forma, João Melo também atenta para a produção discursiva problematizando a relação autor $\mathrm{x}$ narrador x personagem e as perspectivas de narração.
\end{abstract}

Palavras-chave: autoria; espaços urbanos; literatura periférica; literatura angolana

Résumé: Considérant que l'auteur se constitue dans le texte littéraire autant que fonction, en exercent um rôle en relaction au discours, on veut analyser la forme comme les auteurs Sergio Vaz et João Melo répresentent les sujets et les spaces sociaux peu privilégées et aussi comme ils problematisent 1 'auteur aux livres Literatura, pão e poesia (2011) e Filhos da Pátria (2008). On utilisera comme théorie les analyses de Pierre Bourdieu (1996) sur la genèse discursive et les relactions de pouvoir qui la traversent; et de Michel Foucault (2006) dans l'abordage des pouvoirs du discours, ses efects sociaux et son droit d'auteur. Les analyses de Foucault (1970) contribuent à cet étude au sens que le discours c'est pas seulement un moyen de dispute ou traduction de systèmes de domination, mais aussi autant que le vrai objet pour lequel les disputes vont être contestées. Cette contestation pour la legitimité discursive dans la littérature peut être rencontré de façon plus importante dans la production de Sergio Vaz, qui voit la littérature comme le pain du savoir partagée pour les sujets périphériques auxquels ont construit un space pour la consommation des produits littéraires, vue qui sont exclus des moyens de circulation de la culture. Tandis que soit pas de la même maniére, João Melo également

\footnotetext{
${ }^{1}$ Aluna de graduação em Letras - Licenciatura na Universidade Federal do Rio Grande do Sul. E-mail: 00206726@ufrgs.br
} 
observe la production discursive mettant en scène la relaction entre l'auteur $\mathrm{x}$ le narrateur $\mathrm{x}$ le personnage et les perspectives de narration.

Mots- clés: auteur; spaces urbaines; littérature périphérique; littérature angolana.

\section{PERIFERIA, FINA FLOR DA MALANDRAGEM DE UM POVO LINDO E INTELIGENTE}

A literatura é uma dama triste que atravessa a
rua sem olhar para os pedintes, famintos por
conhecimento, que se amontoam nas calçadas
frias da senzala moderna chamada periferia.
Sérgio Vaz

Tratando discursivamente de espaços periféricos urbanos paulistanos e luandenses, Sérgio Vaz - poeta e agitador cultural brasileiro formado nas ruas - e o angolano João Melo narram histórias envolvendo pessoas de diferentes etnias e naturalidades e com distintas trajetórias, que se encontram num mesmo território e nele enfrentam os mesmos obstáculos na vida cotidiana. O espaço urbano contemporâneo que abriga sujeitos diversos é, então, o ponto principal de aproximação entre as obras Literatura Pão e Poesia, de Vaz, e Filhos da Pátria, de Melo, proposto neste estudo. É deste lugar que os autores apresentam personagens que tiveram e têm poucas oportunidades de participação na vida civil "oficial" das grandes cidades.

Abordando a exclusão das populações periféricas do usufruto dos bens culturais, Sérgio Vaz se ocupa de disseminar a poesia através da realização de oficinas em escolas, participação em eventos literários em várias cidades brasileiras - e pelo mundo afora - e da escrita das "histórias de um povo lindo e inteligente". A atuação do poeta, orador e oficineiro Sérgio Vaz elucida o pensamento sobre a produção escrita do autor, pois a pauta de suas iniciativas no meio escolar e cultural do cotidiano da periferia está também colocada em suas crônicas e faz parte, portanto, do cidadão escritor (e autor) Vaz. Autor e não somente escritor porque não só no mundo letrado da palavra escrita ele figura e transfigura, criando arte, mas também no mundo letrado da palavra enunciada oralmente nos saraus e oficinas em que atua, reconhecendo a poesia enquanto uma forma artística que está inserida na vida de adolescentes 
e adultos não só através dos livros canônicos da literatura ocidental - que raramente chegam às periferias - como também em outros suportes, como a música popular.

Dessa forma, Vaz incentiva o consumo e produção artística entre os jovens moradores da periferia urbana de modo a mostrar a literatura como uma prática possível de ser executada por diferentes sujeitos, inclusive os que não estão habituados a circular nos meios intelectuais mais restritos, em que a literatura é divulgada e prestigiada enquanto um capital cultural de requinte, e, portanto, de difícil manuseio e complexo trato. Ao dizer que esta literatura canônica e de prestígio é uma "dama triste", Vaz chama a atenção para o fato de que existe uma literatura que é reconhecida e legitimada como tal e esta não olha para os lados, não vê a situação da periferia, isto é, não circula nesse espaço nem tem um movimento muito representativo no sentido de se voltar para ele, seja para considera-lo como um lugar onde se produz e por onde circula arte, ou um lugar de sujeitos receptores de produções artísticas.

Esta, contudo, não é a única literatura. Há também a literatura do rap, dos saraus, das performances artísticas e dos escritos de outros produtores culturais e literários que não os já reconhecidos enquanto autores; e é para isso que aponta Sérgio Vaz, mostrando a multiplicidade do fazer literário (de seus autores, narradores, personagens, cenários, suportes...) e problematizando o fato de um dado modo de literatura ser legitimado ao ponto de ofuscar ou negar outros modos, que embora se articulem como um novo sistema paralelo ao "legítimo" não são menos prestigiáveis ou menos literários no sentido de elaboração das propriedades estéticas ou quaisquer outras envolvidas no processo de produção da literatura.

João Melo também pauta questões referentes à vida de cidadãos marginalizados - sendo estes angolanos habitantes da periferia de Luanda, os chamados musseques - e seus destinos na Angola pós-independência. Há em Filhos da Pátria, seu terceiro livro de contos, a representação de várias situações que convergem, entre outras coisas, para a reflexão que constitui uma temática observada ao longo dos contos: a angolanidade, a identidade angolana. O que João Melo faz é de certo modo discutir quem são os filhos dessa pátria Angola, o que pensam, o que querem, para onde vão. A escrita deste terceiro livro de contos, segundo Melo, surgiu da necessidade que sentia em retratar tais situações e propor uma discussão sobre um assunto que o instiga: a já mencionada identidade nacional de Angola.

Seus contos, ao abordarem tal tema, atentam para a diversidade étnica nos musseques, a sociedade multicultural e multirracial, a situação precária de miséria cotidiana, o racismo, a 
situação dos brancos angolanos; e mostram os musseques como um lugar incômodo para pessoas de melhor condição social, como no conto "O cortejo". Neste conto, o narrador conta a história de um casamento entre as personagens Leonilde Ferreira da Silva e Rui Carlos Caposso, pertencentes a famílias de "novos ricos angolanos", que prepararam uma cerimônia com muito requinte, o que inclui o uso de uma carruagem para transportar os noivos. É previsto para o fim da cerimônia um cortejo que os levaria na carruagem pelas avenidas da área mais nobre da cidade e ficaria inscrito "nos anais da sociedade luandense", já que um "solene acto" como esse não era comum em Luanda.

Acontece que os planos do casal são desfeitos pelos cavalos da carruagem, que se sensibilizaram ao ver algumas crianças sujas, rotas e descalças na rua, e maquinaram "um plano diabólico" enquanto a cerimônia transcorria. Ao fim da cerimônia, mudaram o trajeto do cortejo, levando os noivos e seus acompanhantes em disparada para bairros mais pobres da cidade. A respeito do impacto que o novo trajeto causou para o casal, o narrador de Melo descreve:

\footnotetext{
"Para os recém-casados, aquela viagem estava a ser um trilhão de vezes pior do que a descida de Dante ao inferno. Pela primeira vez, tinha contacto com um lado da cidade que nunca haviam imaginado. [...] cruzaram com as piores imagens de degradação e miséria que é possível conceber, às quais os homens e mulheres só se adaptaram devido à incrível capacidade de sofrimento e aviltamento do ser humano. Moradias a cair aos pedaços, águas podres alagando as ruas esburacadas, autênticas montanhas de lixo espalhadas por todos os lugares, restos de tudo o que antes fora algum equipamento eventualmente prestável”. (MELO, 2008, p. 145)
}

Ao representar um evento entre famílias ricas luandenses e o quanto essas famílias estão menos sensíveis à situação dos musseques de sua cidade, Melo aponta para a realidade da periferia de Luanda e a falta de visibilidade que esse espaço tem entre os mais abastados. $\mathrm{O}$ autor, no tom irônico que lhe é característico, humaniza os cavalos mais do que as pessoas, conferindo a eles raciocínio e sensibilidade tamanha, que a realidade dos musseques "fazia o coração deles sangrar" (p. 139). Esse olhar à periferia enquanto um espaço que é desprestigiado por grande parte da população da cidade e que tem uma série de problemas com relação às condições de vida de seus habitantes se assemelha ao modo como Sérgio Vaz trata a representação da periferia de São Paulo, apontando problemas cotidianos de sua população, como a violência, as relações no mercado de trabalho, a falta de incentivo à cultura, e, inclusive, tal como João Melo, a insensibilidade da raça humana com relação a essas condições. Segundo Vaz, "se não fosse pelo código penal e os tratados de paz, metade 
da raça humana já teria sido assassinada pela outra metade da raça humana. Que raça!" (p. 144).

É importante não perder de vista que as realidades socioculturais retratadas por cada autor são distintas, contudo, a reflexão que sugerem e a forma como representam seus personagens são em muitos aspectos semelhantes. Ao tratar da população da periferia, Sérgio Vaz diz tratar, como já referido, de "um povo lindo e inteligente", expressão que utiliza não só em suas histórias escritas, como nos saraus que organiza no Bar do Zé Batidão, na zona sul de São Paulo. Ao se referir a seus personagens - igualmente pobres e periféricos, porém locados no continente africano -, João Melo lida com a ironia, mencionando inclusive a pouca visibilidade que os mesmos têm na literatura e na história, como se pode ver nos seguintes trechos: "[angolanos] nome pelo qual é conhecido um povo ignorante localizado a sul do Equador e que se está a matar há quase meio século" e "60\% de habitantes do nosso planeta que sobrevivem com um dólar diário [se desses, como cruelmente ensina o chamado senso comum, não reza a história, por que há-de rezar a literatura?]” (MELO, 2008, p. 77).

Fica claro que Melo chama a atenção para o pouco espaço que os sujeitos periféricos têm na literatura e que essa espécie de apagamento gera também um desconhecimento a respeito desses sujeitos que formam "um povo que se está a matar". Com isso Melo converge para o mesmo ponto de Vaz no sentido de ver a literatura como um veículo fechado a tais personagens do mundo, como uma "dama triste" que não está disposta a ver o seu redor. Esse espaço urbano conflituoso que existe às bordas da matéria-prima da literatura é representado por ambos os escritores como um lugar que reúne pessoas de diversas etnias e procedências, que estão ligadas pela condição a que estão expostas no espaço onde habitam. Segundo Vaz "são brancos, negros, amarelos, gente de todas as cores, dores e lugares" que estão "presos à liberdade" e rindo do cotidiano. Essa mesma pluralidade étnica e também cultural pode ser observada na narração de Melo com relação aos musseques, onde mostra que existem sujeitos vindos de Chipeta, Huambo, Kongo, Lunda do Norte, e de países como Brasil e Rússia. Todos esses personagens são representados enquanto filhos da pátria Angola, o que ressalta o aspecto multicultural da nação e o encontro de culturas locais e estrangeiras que segundo Mantolvani (2007) são tencionadas a ponto de conduzir o entendimento acerca da identidade angolana. 
As personagens de ambos os autores buscam espaço na vida da cidade, e para isso enfrentam uma realidade dura e, em alguns casos, acabam entrando para a criminalidade por falta de perspectivas de vida diferentes. O menino narrador do conto “Tio, mi dá só cem", de João Melo, é um exemplo disso. Tendo os pais mortos durante a guerra, o menino foge para a capital e sobrevive morando na rua e assaltando para poder se alimentar. Ele de certa forma denuncia a violência da qual é vítima ao dizer: "sou um canuco porreiro, não gosto de fazer mal a ninguém, então porquê que todos me fazem mal, um dia ainda vou descobrir, tio" (p.30). Ainda falando de si e de sua situação, o menino atenta para os sacrifícios que enfrenta ressaltando que também sabe caminhar nas águas como Cristo. Esta comparação do sofrimento da população da periferia com o sofrimento de Cristo também ocorre nos escritos de Vaz, em que descrevendo um motorista, o narrador diz que "[Duzão] dirige certo por vias tortas". (2011, p. 19). A alusão cristã dos dois escritores converge para o mesmo ponto: a ênfase dos problemas cotidianos que estão presentes na vida de suas personagens.

\section{A AUTORIA E O PODER DO DISCURSO ÀS MARGENS DA DISSIMULAÇÃ̃O}

João Melo lida com questões de relevância que perpassam a produção discursiva dos agentes políticos, dos profissionais da comunicação e inclusive do fazer literário. As questões articuladas pelo autor dizem respeito à objetividade discursiva, às perspectivas de narração e a relação entre autor e narrador de uma obra. Há em seus contos mais do que narradores, há o autor que intervém na narrativa e se coloca em um plano distante; contudo, ao mesmo tempo em que esse autor se distancia do narrador e dos personagens - faz isso deixando claro que se trata de outra voz e de outra perspectiva que se coloca produzindo um discurso -, ele alerta para o fato de que o distanciamento não é muito concreto. Esse movimento narrativo ambivalente pode ser melhor observado em dois momentos em que se coloca com mais evidência.

No conto "Ngola Kiluanje" encontramos três vozes discursivas: a de uma personagem, do "narrador-autor", e do "narrador-personagem". Fica claro neste ponto que Melo faz uma distinção: "o narrador-autor tem de pedir ao narrador-personagem, aqui, que não se esqueça do que tem para contar" (MELO, 2008, p. 100). O autor intervém duas vezes e alerta que sua voz é de fato uma intervenção na narrativa - "intervenho pela segunda vez [...]" (idem. p. 
107). E essa intervenção, embora marcada como sendo um movimento narrativo de inserção de uma voz exterior ao texto, se coloca como "narrador-autor" para marcar a relação que têm com a narrativa, mostrando que a partir do momento em que a intervenção é concretizada essa voz passa a fazer parte da construção linguística que conduz a história com o status de "narrador". É essa voz, inclusive, que traz ao texto a voz da personagem e tenciona a diferença entre os pontos de vista pelos quais se pode narrar uma história ao dizer que "os leitores têm, portanto, o direito de conhecer o discurso do pai do António".

Em entrevista, João Melo explica um pouco sua problematização da seguinte forma: "Procuro fazer um jogo entre personagens, narradores e autor, tentando mostrar que no fundo a literatura é construção.”. De modo geral, o autor deixa claro em seus escritos, que qualquer escolha que seja feita na construção de uma narrativa é uma escolha que passa por quem a produz: o autor.

Ainda observando o modo de narrar que engloba vozes distintas e, ao mesmo tempo, estreitamente relacionadas, é interessante reparar o conto "O efeito Estufa", em que Melo mais uma vez satiriza a produção discursiva, agora problematizando a relação autor versus narrador. Narrado em terceira pessoa, o conto traz na voz do narrador uma incursão a essa problematização que está instaurada nos contos de Filhos da Pátria:

\footnotetext{
"Os leitores dirão, no final, se fiz dele um retrato sereno e objetivo ou uma mera e grotesca caricatura, motivada pelos meus eventuais e humanos preconceitos. É que, como se sabe a verdadeira distância entre autor e narrador depende somente do grau e do tipo de dissimulação...” (MELO, 2008, p. 61)
}

Observa-se aí que Melo atenta para o fato de que a criação de uma narrativa, de modo geral, e de personagens e narradores, mais especificamente, tem sempre a mediação do autor: um indivíduo histórico e social que ao atuar na produção de um texto (por mais ficcional e, portanto "literário" que seja) usa de sua especificidade (seu ponto de vista e modo de olhar o mundo) e por essa razão há uma linha bastante tênue entre, por exemplo, narrador e autor. E é devido a essa tenacidade que um texto pode apresentar em sua escrita os "eventuais e humanos preconceitos" de um autor. Melo enfatiza a relação fina entre um autor e sua obra a ponto de chamar essa relação de "dissimulação" e mostrar assim o quanto sugere que as perspectivas que coloca ao longo dos seus escritos - do narrador, autor e personagens - estão relacionadas. Dessa forma pode-se concluir que o movimento narrativo de Melo que 
diferencia as vozes do texto e os discursos de cada uma delas serve justamente pra mostrar o quanto essas perspectivas discursivas podem estar relacionadas.

Tais apontamentos de Melo vão de encontro a questões colocadas por Michel Foucault (2004), quando aborda o discurso enquanto objeto de disputa que é controlado desde sua produção:

\footnotetext{
"O discurso (...) não é simplesmente aquilo que manifesta (ou oculta) o desejo; é, também, aquilo que é o objeto de desejo; (...) o discurso não é simplesmente aquilo que traduz as lutas ou os sistemas de dominação, mas aquilo por que, pelo que se luta, o poder pelo qual nos podemos apoderar.” (p. 5)
}

Foucault vê o discurso enquanto um objeto de disputa, já que sua produção e circulação envolve uma relação de poder, em que há exclusão e controle sobre o que está sendo dito ou escrito. Segundo suas considerações, há em toda sociedade uma seleção, organização, redistribuição e controle da produção do discurso; e essas ações sobre o discurso são realizadas por meio de "certo número de procedimentos que têm por função conjurar seus poderes e perigos, dominar seu acontecimento aleatório, esquivar sua pesada e temível materialidade".

O sistema de exclusão do discurso, segundo ele, é historicamente marcado, institucionalmente constrangedor, e funciona com a interdição (os tabus são um exemplo desse procedimento), a segregação entre razão e loucura - o que rejeita um discurso e aceita outro - e a "vontade de verdade", que se caracteriza pela busca de um discurso verdadeiro e acaba por exercer uma pressão e até um poder de coerção sobre outros discursos. Além desses procedimentos mais externos ao discurso, Foucault também aponta outros procedimentos internos que, como os externos, engendram o controle e a exclusão dos discursos. Entre esses procedimentos internos, ele cita o autor (entendendo autor não como uma pessoa física, mas como um modo de ser do discurso, um princípio de agrupamento, uma unidade de significação) e chama a atenção para o fato de que historicamente, na literatura, ao contrário do que acontece na ciência, foi reforçada a necessidade de um autor a quem se possa atribuir o discurso. Há, inclusive, a exigência de que esse discurso, o literário, seja atribuído a alguém.

Ainda no que tange à autoria, Foucault verifica, no texto $O$ que é um autor?, que houve na cultura ocidental uma individualização do autor e se criou uma "categoria fundamental" no fazer científico das ciências humanas: a análise que chama de "o homem-e-a obra". Essa 
individualização é apontada por ele observando alguns princípios, como a noção de uma escrita que "se basta a si mesma" e por esse motivo toma um sentido mais amplo, não se limitando à sua interioridade, mas partindo dessa interioridade de significação para se desdobrar em significações que lhe são exteriores: "a escrita se desenrola como um jogo que vai infalivelmente além de suas regras, e passa assim para fora.".

Esse desdobramento faz parte da abertura de um espaço para que algo seja dito e também para que quem o diga desapareça na medida em que desaparece da escritura as características individuais do sujeito que escreve. Dessa forma o que caracteriza o escritor é a "singularidade de sua ausência", isto é, a forma como ele se faz "não-perceber" no texto. $O$ entendimento de um simples desaparecimento do autor no texto não basta para pensar a escrita na análise de Foucault, mas possibilita observar um texto como portador de uma autoria que se delimita enquanto uma função. De modo geral, o que Foucault propõe é que o nome de um autor não é um nome próprio como outro qualquer ou um simples elemento do discurso, mas exerce uma função em relação ao texto do qual se apropria. Em suas palavras:

\begin{abstract}
"[...] o nome do autor funciona para caracterizar um certo modo de ser do discurso: para um discurso, o fato de haver um nome de autor, o fato de que se possa dizer 'isso foi escrito por tal pessoa' ou 'tal pessoa é o autor disso', indica que esse discurso não é uma palavra cotidiana, indiferente, uma palavra que se afasta, que flutua e passa, uma palavra imediatamente consumível, mas que se trata de uma palavra que deve ser recebida de uma certa maneira e que deve, em uma dada cultura, receber um certo status." (FOUCAULT, 2006, pp. 272-273)
\end{abstract}

Tais considerações de Foucault correspondem ao que coloca Sérgio Vaz quando questiona o cânone literário e propõe um modo diferente de ver poesia, tratando-a não como uma forma artística de muita sofisticação e que só pode ser produzida por quem detém um conhecimento determinado acerca do assunto - e por isso têm poder e autoridade para poder produzi-la - mas como um acontecimento cotidiano para o qual todos estão habilitados a participar, seja nos saraus da Cooperifa no Bar do Zé Batidão ou em qualquer espaço. Vaz coloca os sujeitos da periferia enquanto autores, que embora não sejam prestigiados pelo cânone, também têm legitimidade no meio literário para serem reconhecidos como produtores de Literatura, com "L" maiúsculo e sem adjetivos que classificam em nichos como o "periférico" ou "marginal".

Vaz, atento às relações de poder que se estabelecem na produção discursiva e ao status que uma cultura atribui a um ou outro autor (é isso que acontece na seleção de um cânone, por 
exemplo), leva a poesia para a rua, e delimita bem a diferença entre duas formas de circulação literária ao escrever que a poesia do sarau da Cooperifa "não tem nada a ver com poesia de prateleira de biblioteca. Tem a ver com a palavra da rua, é boca sem dente e descamisada (...). É letra que corre sim pelas calçadas de chinelo de dedos". (2011, p. 164)

Essas tensões das quais trata Sérgio Vaz também podem ser analisadas à luz do que Bourdieu escreve ao abordar as condições sociais de produções discursivas. Para Bourdieu, todo ato de fala é uma conjuntura, um encontro de séries: capacidade linguística (gramatical) + capacidade social (de adequação) do locutor + as estruturas de mercado (sanções e censuras). Dessa forma, Bourdieu reconhece que a literatura está inserida em um campo de poder, já que existe um mercado de circulação e estruturação da literatura que "contribui para formar, não só o valor simbólico, mas também o sentido do discurso" (1996, p.25).

\section{CONSIDERAÇÕES FINAIS}

Observando a representação dos espaços urbanos periféricos, é possível notar que tanto Sérgio Vaz quanto João Melo apresentam ao leitor um ambiente rico no que diz respeito à existência de personagens de culturas diversas, mas pobre no que se refere às precárias condições de vida em um lugar onde o acesso a serviços como o recolhimento de lixo, o saneamento básico, a qualidade da moradia ou a circulação de bens culturais, é bastante restrito. Os autores apresentam uma realidade tumultuada, em que os sujeitos moradores da periferia lidam cotidianamente com relações de poder que têm ressonância não apenas nas relações interpessoais - que se realizam em situações como o trabalho ou o convívio com outros sujeitos que agem com desprezo ou descaso em relação à periferia das grandes cidades - mas também nos discursos que são produzidos na sociedade.

A relação de poder que enfrentam nos discursos sociais - e dentro desse conjunto de discursos, o literário, principalmente - se dá na forma de exclusão desses sujeitos e do espaço em que abitam. No caso da literatura, a exclusão acontece desde a produção discursiva, até a temática do discurso ou a recepção, ou seja, a participação dos sujeitos periféricos na literatura canônica é restrita na condição de autores, personagens ou mesmo de leitores. Há, como aponta Foucault, um controle social da produção discursiva, o que articula 
procedimentos interiores e exteriores a um discurso de modo a restringir sua produção, aceitação e circulação a meios específicos.

O que encontramos nos escritos de Vaz e de Melo é um desvelamento e problematização dessas relações por meio da multiplicidade de vozes que ambos os escritores inserem nos seus textos, mostrando diferentes perspectivas que podem estar presentes no discurso literário. Melo trabalha com essa multiplicidade fazendo a distinção entre narrador, autor e personagem em sua narração. Tal distinção serve para evidenciar a relação entre as vozes do texto e, além disso, as distinções reais que se fazem entre autor e narrador no plano da crítica literária.

Vaz apresenta a literatura "marginal" como um discurso que se relaciona com o discurso da literatura canônica. O autor pauta com maior contundência a disputa por legitimidade discursiva no meio literário, fazendo a diferenciação entre a "literatura de prateleira" e a "literatura da rua" e questionando quem pode ser considerado autor. Ao fazer isso, Vaz lida com o conceito de autor apresentado por Foucault, que analisa a autoria não como a atribuição de um nome próprio qualquer, mas como um elemento que tem uma função, desempenhando um papel com relação ao discurso. E essa função é estabelecida, como analisa Bourdieu, em um mercado de circulação literária tencionado por relações de poder. Em suma, Vaz, Foucault, Bourdieu e Melo apontam, cada um de sua maneira, para as tensões existentes na produção de um discurso - que envolvem a existência de status autoral, disputa por legitimidade, sanções e censuras.

\section{REFERÊNCIAS}

BOURDIEU, Pierre. A Economia das trocas Linguísticas: O que falar quer dizer, São Paulo: Editora da Universidade de São Paulo, 1996.

, Pierre. As regras da arte. Tradução Maria Lúcia Machado. São Paulo: Companhia da Letras, 1996.

FOUCAULT, Michel. O que é um autor? In: Ditos e Escritos III - Estética: Literatura e pintura, Música e cinema. Rio de Janeiro: Forense Universitária, 2006. pp. 264-298 
, Michel. A ordem do discurso. São Paulo: Loyola, 2004.

MANTOLVANI, Rosângela Manhas. A pátria de João Melo: Um estado multicultural. Revista Crioula, $\mathrm{n}^{\mathrm{o}}$ 2, novembro de 2007.

MELO, João. Filhos da Pátria. Rio de Janeiro: Record, 2008.

VAZ, Sérgio. Literatura, pão e poesia. São Paulo: Global,2011. 